\title{
Possible induction of systemic lupus erythematosus by human parvovirus
}

\author{
A P Cope, A Jones, M Brozovic, M S Shafi, R N Maini
}

\begin{abstract}
A 59 year old woman presented with an influenza-like illness preceding signs and symptoms strongly suggestive of systemic lupus erythematosus (SLE), which progressed over several months. Owing to these influenza-like symptoms, a viral cause of her illness was sought. Human parvovirus B19 serology was positive and antibodies to DNA were detected by two different methods. This patient is believed to be the first report of human parvovirus B19 infection coinciding with the onset of SLE. The evidence for B19 virus and the part it plays in autoimmunity and arthritis is discussed.
\end{abstract}

Similarities between systemic lupus erythematosus (SLE) and human parvovirus (B19) infection are striking, and although B19 has been implicated in autoimmune diseases, there has been no previous report of this virus being a possible initiating agent in the pathogenesis of SLE. We describe here a patient whose B19 infection coincided with the onset of SLE.

\section{Case report}

A 59 year old British woman, previously well, presented with a three week history of pain and stiffness in the thumbs, wrists, and shoulders. This followed an influenza-like illness with arthralgia, fever, myalgia, but no rash. Pain and swelling in the feet and ankles followed over the next few weeks. Her full blood count revealed haemoglobin $95 \mathrm{~g} / \mathrm{l}$, white blood cell count $2 \cdot 4 \times 10^{9} / 1$, lymphopenia being a feature, platelets

Department of Rheumatology, Charing Cross Hospital, Fulham, London W6, United Kingdom

A P Cope

A Jones

R N Maini

Department of

Haematology,

Central Middlesex

Hospital,

Acton Lane, Park Royal,

London NW10 7NS,

United Kingdom

M Brozovic

Department of

Microbiology,

Central Middlesex

Hospital, Acton Lane, Park Royal,

London NW10 7NS,

United Kingdom

M S Shafi

Correspondence to

Dr Cope.

Accepted for publication

20 September 1991
$186 \times 10^{9} / 1$, and erythrocyte sedimentation rate $36 \mathrm{~mm} /$ hour.

Two months after onset, her joint symptoms became worse and she developed febrile episodes. Splenomegaly was noted. Her autoantibody profile showed a positive antinuclear factor with a titre of 1/2560 and a positive titre for antibodies to DNA. As part of the routine investigation of febrile illness associated with arthropathy, a viral serological examination was performed and showed positive IgM to human referred to the rheumatology unit at Charing Cross Hospital.

By this time, one month later, her joints had improved spontaneously, and she had no early morning stiffness, rashes, alopecia, nor photosensitivity. She reported several episodes of pleuritic chest pain and still felt lethargic, with aching in her shoulders. During her stay in hospital, she was intermittently febrile $(36 \cdot 5-$ parvovirus B19 in her serum sample. She was
$39 \cdot 2^{\circ} \mathrm{C}$ ) and had a malar rash. Her blood pressure was $170 / 95 \mathrm{mmHg}$ and late inspiratory crackles were heard in her chest at the left base. Her spleen was palpable $5 \mathrm{~cm}$ below the costal margin. Apart from diffuse muscle wasting the only abnormality of her musculoskeletal system was a slight restriction of abduction and rotation of the shoulders, with minimal synovitis. Neurological examination was normal.

Laboratory investigations were as follows: haemoglobin $79 \mathrm{~g} / \mathrm{l}$, white cell count $4 \cdot 3 \times 10^{9} / 1$ with lymphopenia, platelets $141 \times 10^{9} / \mathrm{l}$ ), erythrocyte sedimentation rate $28 \mathrm{~mm} /$ hour, direct Coombs' test negative, biochemical profile including liver and thyroid function tests and creatinine phosphokinase normal. There was no evidence of renal impairment on the basis of serum electrolytes, 24 hour urinary protein excretion, creatinine clearance, and microscopy of a spun sediment of a midstream sample of urine. The latex test was positive (RAHA 1/320), and fluorescent antinuclear antibodies were strongly positive (homogenous pattern). Antibodies to double stranded DNA were detectable by a positive result in the Crithidia lucillae immunofluorescent test and by increased levels $(26 \mathrm{U} / \mathrm{ml})$ in a Farr assay (normal range less than $7 \mathrm{U} / \mathrm{ml}$ ). Antibodies to single stranded DNA, DNA protein, extractable nuclear antigens, and cardiolipin were all negative or normal. Immunoglobulins and $\mathrm{C} 3$ and $\mathrm{C} 4$ components of complement were in the normal range. $\mathrm{C}$ reactive protein was increased at 38 $\mathrm{mg} / \mathrm{l}$. Her chest radiograph showed linear shadows at the left lung base.

Serial serum specimens were tested for IgM specific to parvovirus $B 19$ by radioimmunoassay (RIA) with monoclonal antibodies. Levels of specific IgM antibodies gradually decreased from a peak of 8.0 RIA units (normal less than 3.3 RIA units), becoming undetectable in the sample taken three months after presentation. The specificity of the $\mathrm{B} 19$ radioimmunoassay was confirmed by previous absorption of $\operatorname{IgM}$ rheumatoid factor, thus excluding false positive results. No other infective cause for persistent fever was found despite repeated cultures of blood, urine, throat swabs, and sputa. There was no evidence of recent infection with hepatitis B, rubella, mumps, nor brucella. A synovial biopsy sample was considered at this time, but in view of the lack of synovitis was thought not to be necessary.

The patient was treated with prednisolone $(0.75 \mathrm{mg} / \mathrm{kg})$ and hydroxychloroquine with good clinical response, her fever settling and lethargy improving. Within six weeks her symptoms had largely resolved, though clinically 
left basal crackles persisted and a pleural friction rub was noted at the right lung base. Her haemoglobin had increased to $131 \mathrm{~g} / \mathrm{l}$ with an erythrocyte sedimentation rate of $10 \mathrm{~mm} /$ hour, and all immunological parameters including levels of antibody to double stranded DNA had returned to normal.

\section{Discussion}

We have described a patient whose symptoms began at the onset of an acute B19 virus infection, and who shortly afterwards developed SLE. It could equally describe a patient with recent onset SLE who had an intercurrent B19 infection.

Similarities between the symptoms of the two diseases are not commonly remarked upon, but include fever, malaise, myalgia, arthritis, lymphadenopathy, rash, and bone marrow suppression. Two questions arise from this: what is the evidence for the association between B19 infection and autoimmune disease, and could this patient's connective tissue disease have been precipitated by B19 infection?

Recognised clinical manifestations of $\mathrm{B}^{1} 9^{1}{ }^{2}$ include erythema infectiosum (fifth disease), ${ }^{3}$ aplastic crisis in the chronic haemolytic anaemias such as sickle cell disease,${ }^{4}$ intrauterine fetal death, ${ }^{5}$ and acute and persistent polyarthropathy. ${ }^{6}$ Documented examples of B19 infection in autoimmune diseases are less common. Coombs' positive autoimmune haemolytic anaemia as detected by reticulocytopenia has been linked to parvovirus in a number of cases, ${ }^{7-10}$ but in many instances the infection has been thought to be responsible for the acute reticulocytopenia rather than for initiating the autoimmune process.

Rowe et al have described in detail 11 cases of confirmed B19 infection, one of whom presented acutely with autoimmune haemolytic anaemia. ${ }^{7}$ Another was weakly positive for antinuclear factor, and had joint symptoms persisting for longer than five months. A third patient with arthritis was rheumatoid factor positive.

There is more evidence for B19 causing acute or persisting polyarthropathy and small series from early synovitis clinics have been described in some detail. ${ }^{5}$ Most cases occur in women aged 30-40 years, often starting in the hand or knee joints and spreading, causing considerable pain and stiffness. Symptoms are preceded by an influenza-like illness in less than $50 \%$ of patients. Interestingly, arthralgia in fifth disease of childhood is less common, and B19 infection has only rarely been described in juvenile chronic arthritis. ${ }^{11}$

The presence of recent $\mathrm{B} 19$ infection in two patients with early rheumatoid arthritis (RA) and four patients with acute inflammatory arthritis has been described. ${ }^{12}$ This finding, in conjunction with evidence of previous B19 infection being found more often in patients with RA compared with controls, provides some evidence for the arthritogenic potential of B19 in predisposed subjects. Further, there has been interest in the finding of an antiserum to the parvovirus-like RA-1 virus, reacting with homogenates of synovium from patients with RA but not osteoarthritis. ${ }^{13}$ Antiserum to B19, however, did not react with the same homogenates, refuting previous suggestions that the RA-1 virus was related to $B 19$.

With respect to SLE, Soloninka et al have shown the presence of increased levels of autoantibodies, to double and single stranded DNA in particular, in 68 subjects recovering from parvovirus infection. ${ }^{14}$ From their data they proposed that parvovirus may accompany a transient, subclinical autoimmune state; our patient, however, seems to have taken this proposal one step further by showing persistent, clinically detectable autoimmunity.

Clearly the methods of detecting recent B19 infection are in part responsible for the difficulties in establishing its part in the aetiopathogenesis of autoimmune diseases and arthritis in particular. With the help of B19 cDNA probes it may be possible in the near future to assess patients in greater detail, especially those with persistent arthropathy and prolonged IgM responses.

To our knowledge this is the first documented case of parvovirus B19 infection coinciding with the onset of SLE. Although it is possible that the patient developed an incidental B19 infection, it is conceivable that B19 was responsible for inducing her autoimmune connective tissue disease.

1 Thurn J. Human parvovirus B19: historical and critical review. Rev Infect Dis 1988; 10: 1005-11.

2 Tratschin J D, Siegl G. Parvoviruses as pathogenic agents in man. Schweiz Med Wochenschr 1988; 118: 347-53.

3 Anderson M J, Jones S E, Fisher-Hoch S P, et al. Human parvovirus: the cause of erythema infectiosum (fifth disease)? Lancet 1983; i: 1378 .

4 Tomiyana J, Adachi Y, Hanada T, Matsunaga Y. Human parvovirus B19-induced aplastic crisis in autoimmun haemolytic anaemia. Br $\mathcal{F}$ Haematol 1988; 69: 288-9.

5 Anand A, Gray E S, Brown T, et al. Human parvovirus infection in pregnancy and hydrops foetalis. $N$ Engl $\mathcal{F}$ Med 1987; 316: 183-6.

6 White D G, Mortimer P P, Blake D R, Wolf A D, et al Human parvovirus arthropathy. Lancet 1985; i: 419-2

7 Rowe I F, Deans A C, Midgeley J, Anderson M J, Keat A C. Parvovirus infection in hospital practice. $\mathrm{Br} \mathcal{Y}$ Rheumatol 1987; 26: 13-6.

8 Bertrand Y, Lefrere J J, Leverger G, et al. Autoimmune haemolytic anaemia revealed by erythroblastopenia linked to parvovirus infection. Arch Fr Pediatr 1986; 43: 409-11.

9 to parvovirus infection. Arch Fr Pediatr 1986; 43: 409-11. haemolytic anaemia revealed by human parvovirus linked haemolytic anaemia revealed by human parvc

10 Schwarz T F, Roggendorf M, Janka-Schaub G. Aplastic crisis caused by parvovirus B19 infection. Eur $\mathcal{F}$ Clin Microbiol Infect Dis 1988; 7: 87-8.

11 Schwartz T F, Roggendorf M, Suschke H, Deinhardt F. Human parvovirus B19 infection and juvenile chronic polyarthritis. Infection 1987; 15: 264-5.

2 Cohen B J, Buckley M M, Clewley J P, Jones V E, Puttick A H, Jacoby $R$ K. Human parvovirus infection in early rheumatoid arthritis and inflammatory arthritis. Ann Rheum Dis 1986; 45: 832-8.

13 Stierle G, Brown K A, Rainsford S G, et al. Parvovirus associated antigen in the synovial membrane of patients with rheumatoid arthritis. Ann Rheum Dis 1987; 46: 219-23.

14 Soloninka C A, Anderson M J, Laskin C A. AntiDNA and anti-lymphocyte antibodies during acute infection with human parvovirus B19. I Rheumatol 1989; 16: 777-81. 